\title{
Docetaxel Accumulates in Lymphatic Circulation Following Subcutaneous Delivery Compared to Intravenous Delivery in Rats
}

\author{
DEANNA R. WORLEY ${ }^{1,2}$, RYAN J. HANSEN ${ }^{1,2}$, LUKE A. WITTENBURG ${ }^{1,2}$, \\ LAURA S. CHUBB ${ }^{2}$ and DANIEL L. GUSTAFSON ${ }^{1,2}$ \\ ${ }^{1}$ Department of Clinical Sciences, Colorado State University, Fort Collins, CO, U.S.A.; \\ ${ }^{2}$ Flint Animal Cancer Center, Colorado State University, Fort Collins, CO, U.S.A.
}

\begin{abstract}
Background: The circulatory pathway for particles deposited outside of blood capillaries has not been well characterized for non-traditionally-delivered chemotherapeutics. Materials and Methods: Blood and lymph pharmacokinetics of docetaxel $(5 \mathrm{mg} / \mathrm{kg})$ and carboplatin (14 and $28 \mathrm{mg} / \mathrm{kg}$ ) following subcutaneous (s.c.) versus intravenous (i.v.) delivery were determined in a rodent model with catheterizations of both the thoracic lymphatic duct and jugular vein for prolonged synchronous blood and lymph sampling. Results: Subcutaneous docetaxel demonstrates preferential lymphatic accumulation based on the area under the time-concentration curve $\left(A U C_{0-}\right.$ 24h) whereas i.v. docetaxel resulted in a greater plasma maximum concentration measured $\left(C_{\max }\right)$. The apparent elimination half-life $\left(t_{1 / 2}\right)$ in lymph for docetaxel is greater following i.v. or s.c. delivery compared to $t_{1 / 2}$ in blood. Carboplatin demonstrates a dose-dependent increase in plasma $C_{\text {max }}$ regardless of delivery route; the total carboplatin exposure over $24 \mathrm{~h}$ in lymph and plasma are comparable. Conclusion: Subcutaneous docetaxel achieves lymphatic accumulation greater than that of i.v. delivery.
\end{abstract}

The pharmacokinetics of intravenous (i.v.) chemotherapy, including carboplatin and docetaxel, are well delineated. The use of $i . v$. chemotherapy is an indisputable pillar of cancer therapy; however, it can be associated with unfavorable

This article is freely accessible online.

Correspondence to: Deanna R. Worley, Department of Clinical Sciences, Colorado State University, 1620 Campus Delivery, Fort Collins, CO, 80523, U.S.A. Tel: +1 9702974423, Fax: +1 9702971254,e-mail: dworley@colostate.edu

Key Words: Lymph, subcutaneous administration, docetaxel pharmacokinetics, carboplatin pharmacokinetics. systemic toxicity. The application of locally delivered chemotherapy, whether subcutaneous (s.c.), surgical placement or intracavitary routes, similarly yields beneficial effects, yet with decreased systemic toxicity and positive tumor control at dosages less than traditionally given i.v. (16). A possible reason may be increasing drug levels within the lymphatic system. The lymphatic system is an integral scavenge system or accessory route of fluid and large particulate matter accumulating in the interstitial space for return to the blood (7). While drugs have been targeted for delivery to the lymph, either by route of delivery or by specific formulation, drug levels in the lymph fluid have not been well characterized to date for non-traditionally delivered chemotherapy agents (8-10).

The lymphatic system differs from the vascular system with its unidirectional flow of lipophilic-rich fluid, albumin, lymphocytes and scavenged cells from peripheral lymphatics through lymph nodes to collecting lymph ducts prior to emptying into the cranial vena cava. The lymphatic system is also a pathway for metastasis; the presence of metastasis in lymph nodes is of clinical import (11). As revealed in breast cancer, tumor production of lymphangiogenic growth factors stimulates lymphatic vessel formation and resulting in trafficking of metastatic cells through lymph fluid that aids their survival via protective high concentrations of hyaluronic acid and low flow rates (12). Local delivery of chemotherapy, demonstrating preferential lymphatic uptake into or near tumors or resection sites, may be beneficial to more successfully treat cancers having locoregional lymphatic metastasis.

Recent research efforts have focused attention on the strategy of s.c. drug delivery and enhancing lymphatic drug uptake (13-16). These strategies include use of lipoproteins, formulation of dendritic polymers, microspheres, micelles and liposome encapsulation (17-20). Other efforts have included direct s.c. deposition of desired drug or protein (3, 14). The size of s.c. drug particles and structures have also 
been increased to preclude direct vascular access for obligate entry into the lymphatic system and is the strategy for lymphatic targeting with binding drugs to large dendrimers. Another approach has altered drug hydrophobicity of smaller molecules to improve targeting to lipophilic lymph $(16,21)$. Thus, there is practicality and importance in delineating the lymphatic and hemovascular pharmacokinetics and bioavailability of a drug when delivered both i.v. and s.c.

The purpose of this study was to describe and compare the lymphatic and hemovascular pharmacokinetics of two common and physiochemically different chemotherapeutics, docetaxel and carboplatin, when delivered s.c. versus i.v. in a rodent model with catheterizations of both the thoracic lymphatic duct and jugular vein for prolonged synchronous blood and lymph sampling. We hypothesized that docetaxel and carboplatin, when administered s.c., would accumulate within lymph fluid resulting in delayed and sustained vascular concentrations as compared to the traditional i.v. delivery.

\section{Materials and Methods}

Animals. Study underwent ethical review and was approved by the Colorado State University Institutional Animal Care and Use Committee (protocol\# 12-3320A), according to the United States Department of Agriculture/Animal and Plant Health Inspection Service Animal Welfare Act and Public Health Service Policy. The care and use of study animals complied with local animal welfare laws, guidelines and policies. Thirty-two male Sprague Dawley rats (Charles River Laboratories, Inc., Wilmington, MA, USA) were used.

Surgical model. Each rat was premedicated with buprenorphine $(0.05 \mathrm{mg} / \mathrm{kg}$ s.c. $)$, either carprofen $(1 \mathrm{mg} / \mathrm{kg}$ s.c. $)$ or meloxicam $(0.2$ $\mathrm{mg} / \mathrm{kg})$, and dexmedetomidine $(0.3 \mathrm{mg} / \mathrm{kg} \mathrm{IP})$ and induced with isoflurane via face mask. A 24-gauge over the needle catheter was placed in the tail vein for continuous intravenous delivery of sterile $0.09 \%$ saline for surgical support. Following aseptic preparation, a left paracostal laparotomy was done. Sterile methylene blue dye, $0.01 \mathrm{ml}(10 \mathrm{mg} / \mathrm{ml})$, was injected into a mesenteric lymph node to aid in thoracic duct coloration and localization. The abdominal portion of the thoracic lymph duct was isolated immediately cranial to the left kidney, adrenal gland and cisterna chylii. A $60 \mathrm{~cm}$ length of sterile $2 \mathrm{Fr}$ polyurethane tubing (flushed with heparinized saline) was tunneled from the abdominal cavity through the left lateral flank with an 18-gauge needle. The thoracic duct was isolated, incised and the polyurethane catheter was threaded into the thoracic duct and secured with a combination of 6.0 encircling nylon suture and sterile N-butyl cyanoacrylate adhesive. The presence of free flowing lymph was confirmed via visualization of passive fluid movement from the free end of the polyurethane catheter. The abdominal cavity was closed with 4-0 polyglyconate in two layers and covered with wound clips. The polyurethane catheter was tunneled to exit dorsal to the cervical region. The rat was repositioned and the ventral cervical region was aseptically prepared. The left jugular vein was isolated and a second $60 \mathrm{~cm}$ length of $2 \mathrm{Fr}$ sterile polyurethane tubing flushed with heparinized

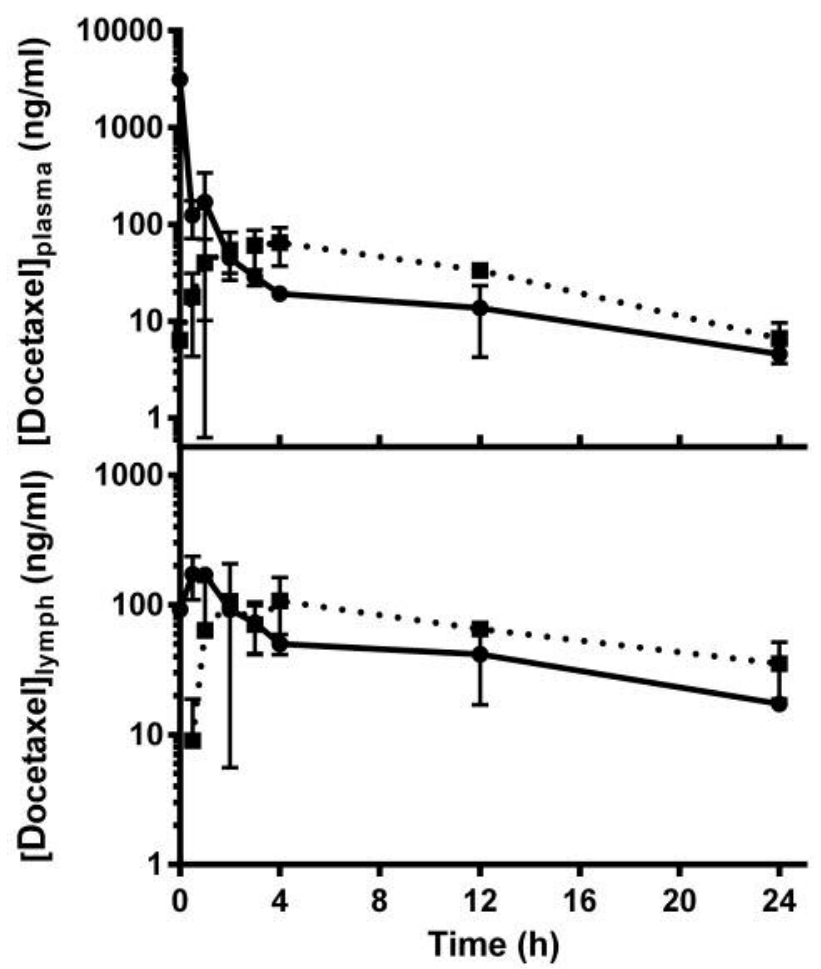

Figure 1. Time concentration curves of docetaxel ( $5 \mathrm{mg} / \mathrm{kg}$ ) in plasma (top graph) and lymph (bottom graph) when delivered either i.v. (solid line) or s.c. (dotted line).

saline was threaded and secured within the left jugular vein with two 6-0 nylon encircling ligatures. The wound was closed in a single intradermal layer with 4-0 polyglyconate. The catheter was tunneled to exit dorsal to the cervical region adjacent to the thoracic duct catheter. A tethered silicone harness was fitted to each animal such that the catheters were protected within the spring wire tether to exit through the floor of a rat housing box. The tethered animal was allowed unrestricted movement within the box and free access to food and water ad libitum. Tethered restraint permitted non-stressful distance collection for serial sample collections. Lymph was allowed to flow continuously and passively at a gravity dependent distance below the rat to prevent clotting. All animals received buprenorphine $(0.05 \mathrm{mg} / \mathrm{kg}$ s.c. $\mathrm{q} 8 \mathrm{~h})$ for additional analgesia.

Sample collection. Carboplatin (14 or $28 \mathrm{mg} / \mathrm{kg}$ ) or docetaxel ( 5 $\mathrm{mg} / \mathrm{kg}$ ) was injected either into the right subcutaneous mammary fat pad or intravenously through the tail vein catheter. Lymph and blood were collected at $0,0.5,1,2,3,4,12$ and $24 \mathrm{~h}$. As lymph was free flowing, it was collected for ten-minute intervals, starting five minutes prior to blood collection times. Blood samples were collected via a three syringe technique. Briefly, a syringe filled with $0.05 \mathrm{ml}$ heparinized saline $(50 \mathrm{IU} / \mathrm{ml})$ was used to draw out $0.3 \mathrm{ml}$ of reserved blood. A second syringe, rinsed with $143 \mathrm{IU}$ heparin $/ \mathrm{ml}$ saline, was used to collect $0.15 \mathrm{ml}$ of blood for analysis. Reserved blood was returned through the jugular catheter and the catheter was flushed with $0.2 \mathrm{ml}$ heparinized saline $(50 \mathrm{IU} / \mathrm{ml})$ and plugged. 
Table I. Non-compartmental pharmacokinetics of docetaxel $(5 \mathrm{mg} / \mathrm{kg})$ in plasma and lymph when delivered either i.v. or s.c.

Docetaxel $5 \mathrm{mg} / \mathrm{kg}$

\begin{tabular}{|c|c|c|c|c|c|}
\hline \multirow[b]{2}{*}{ PK paramete } & & \multicolumn{2}{|c|}{ i.v. Admin } & \multicolumn{2}{|c|}{ s.c. Admin } \\
\hline & & $\begin{array}{c}\text { Plasma } \\
\text { ave (S.D.; n) }\end{array}$ & $\begin{array}{c}\text { Lymph } \\
\text { ave (S.D.; n) }\end{array}$ & $\begin{array}{c}\text { Plasma } \\
\text { ave (S.D.; n) }\end{array}$ & $\begin{array}{c}\text { Lymph } \\
\text { ave (S.D.; n) }\end{array}$ \\
\hline $\mathrm{C}_{\max }$ & $\mathrm{ng} / \mathrm{ml}$ & $2857(560 ; 3)$ & $172(63 ; 3)$ & $80.8(19.0 ; 5)$ & $161(54 ; 3)$ \\
\hline $\mathrm{T}_{\max }$ & $\mathrm{h}$ & - & $0.5(0 ; 3)$ & $3.0(1.2 ; 5)$ & $2.3(1.5 ; 3)$ \\
\hline$\lambda_{\mathrm{z}}$ & $1 / \mathrm{h}$ & $0.073(0.005 ; 2)$ & $0.054(0.013 ; 2)$ & $0.114(0.024 ; 5)$ & $0.084(0.007 ; 2)$ \\
\hline$t_{1 / 2}$ & $\mathrm{~h}$ & $9.6(0.7 ; 2)$ & $13.2(3.1 ; 2)$ & $6.3(1.3 ; 5)$ & $8.3(0.7 ; 2)$ \\
\hline $\mathrm{AUC}_{0-24 \mathrm{~h}}$ & $\mathrm{~h} * \mathrm{ng} / \mathrm{ml}$ & $1297(344 ; 2)$ & $1022(339 ; 2)$ & $799(226 ; 5)$ & $1563(216 ; 3)$ \\
\hline $\mathrm{AUC}_{0 \text {-inf }}$ & $\mathrm{h} * \mathrm{ng} / \mathrm{ml}$ & $1360(331 ; 2)$ & $1508(207 ; 2)$ & $861(239 ; 5)$ & $1986(225 ; 2)$ \\
\hline $\mathrm{V}_{\mathrm{d}}$ & $\mathrm{L}$ & $20.3(7.8 ; 2)$ & & $13.4(6.6 ; 5)$ & \\
\hline $\mathrm{Cl}$ & $\mathrm{ml} / \mathrm{h}$ & $24.2(7.6 ; 2)$ & & $23.7(8.4 ; 5)$ & \\
\hline MRT & $\min$ & $135(18 ; 2)$ & $449(54 ; 2)$ & $405(91 ; 5)$ & $598(118 ; 3)$ \\
\hline $\mathrm{F}$ & $\%$ & & & $61.6 \%$ & \\
\hline
\end{tabular}

Admin, administration; PK, pharmacokinetic; ave, average; S.D., standard deviation; $\mathrm{C}_{\max }$, maximum plasma concentration observed; $\mathrm{T}_{\text {max }}$, time of maximum plasma concentration observed; $\lambda_{\mathrm{z}}$, elimination rate constant; $\mathrm{AUC}_{0-24 \mathrm{~h}}$, area under the plasma concentration time curve from 0 to 24 $\mathrm{h} ; \mathrm{AUC}_{0 \text {-inf }}$, area under the plasma concentration time curve from $0 \mathrm{~h}$ to infinity; $\mathrm{V}_{\mathrm{d}}$, volume of distribution; $\mathrm{Cl}$, clearance; MRT, mean residence time; F, bioavailability.

Blood samples once collected were centrifuged for 10 minutes and plasma was obtained. Plasma and lymph aliquots were frozen at $-80^{\circ} \mathrm{C}$ until analysis. Rats were humanely euthanized at the $24-\mathrm{h}$ time point.

Pharmacokinectics and sample analysis. Docetaxel concentrations in lymph and plasma were determined via liquid chromatographytandem mass spectrometry (LC-MS/MS) as described previously by Gustafson et al. (22). Total platinum quantification in lymph and plasma was determined via total platinum analysis by inductively coupled plasma mass spectrometry. Prior to shipping total platinum samples to Midwest Laboratories Inc (Omaha, NE, USA) for inductively coupled plasma mass spectrometry (ICP-MS) analysis, $50-100 \mu$ of lymph or plasma was tared in $15 \mathrm{ml}$ conical tubes to which 10 volumes of freshly prepared aqua regia (concentrated nitric acid and hydrochloric acid in a 1:3 (v:v) ratio) were added and incubated overnight at room temperature. The following day samples were diluted 1:2 with Milli-Q water and shipped to Midwest Laboratories. Amounts of aqua regia and Milli-Q were determined gravimetrically and total platinum concentrations are reported in $\mu \mathrm{g} / \mathrm{ml}$ of plasma or lymph.

Pharmacokinetic parameters were determined via noncompartmental analysis performed with Phoenix ${ }^{\mathrm{TM}}$ WinNonlin ${ }^{\circledR}$ v6.3 (Certara Inc., Princeton, NJ, USA). Plasma and lymph values for docetaxel and plasma values for carboplatin are reported as the mean and standard deviation (SD) of individual rat pharmacokinetic parameters. Maximum plasma concentration $\left(\mathrm{C}_{\max }\right)$ data was available for all rats; only rats with plasma/lymph concentrations measured out to $24 \mathrm{~h}$ were used for estimation of elimination rate constant $\left(\lambda_{\mathrm{z}}\right)$, half life $\left(\mathrm{t}_{1 / 2}\right)$ and area under the plasma concentration time curve $\left(\mathrm{AUC}_{0-24 \mathrm{~h}}\right)$. Due to difficulties during sampling of lymph for carboplatin treated rats, not all rats were able to provide a lymph sample at each time point and, thus, full time course data for each rat could not be used for pharmacokinetic (PK) analysis. A noncompartmental sparse sampling method was used to obtain one mean concentration-time profile, Phoenix ${ }^{\mathrm{TM}}$ WinNonlin ${ }^{\circledR}$ v6.3 (Certara Inc.). This method utilizes an algorithm that allows intersubject variability on $\mathrm{Cmax}$ and $\mathrm{AUC}_{0-24 \mathrm{~h}}$ to be obtained; thus, the $\mathrm{Cmax}_{\text {and }} \mathrm{AUC}_{0-24 \mathrm{~h}}$ for lymph data in carboplatin treated mice are reported as Mean \pm standard error of the mean (SEM). Bioavailability for s.c. delivered docetaxel and carboplatin were determined by the ratio of $\mathrm{AUC}_{0-24}$ values for s.c. administration divided by values for $i . v$. administration and is reported as a percent.

Statistical analysis. Comparisons of plasma pharmacokinetic parameters between administration routes and between plasma and lymph parameters for docetaxel administration were made using two-tailed student's $t$-test. Significance was determined as a $p$-value $<0.05$. Statistical analysis was carried out with Graphpad Prism ${ }^{\circledR}$ (GraphPad Software, Inc., La Jolla, CA, USA).

\section{Results}

Plasma and lymph disposition of docetaxel following i.v. and s.c. administration. Docetaxel administered s.c. demonstrates preferential lymphatic accumulation when comparing total exposure in lymph and plasma from 0 to $24 \mathrm{~h}\left(\mathrm{AUC}_{0-24 \mathrm{~h}}\right)$ via both administration routes (Figure 1, Table I). The $\mathrm{AUC}_{0-24 \mathrm{~h}}$ in the lymph was $1,563 \pm 216 \mathrm{~h} * \mathrm{ng} / \mathrm{ml}$ when docetaxel was administered s.c. compared to $1,022 \pm 339 \mathrm{~h} * \mathrm{ng} / \mathrm{ml}$ following i.v. delivery $(p=0.110)$. There was a larger difference in the AUC values for plasma between the two routes with i.v. and s.c. having values of $1,297 \pm 344$ and $799 \pm 226 \mathrm{~h} * \mathrm{ng} / \mathrm{ml}$, respectively (Table I). This difference was not statistically significant ( $p=0.066)$ but the small number of animals with full time course samples available in the $i . v$. group $(\mathrm{n}=2)$ may have been the cause of this result. The ratio of docetaxel exposure in the 


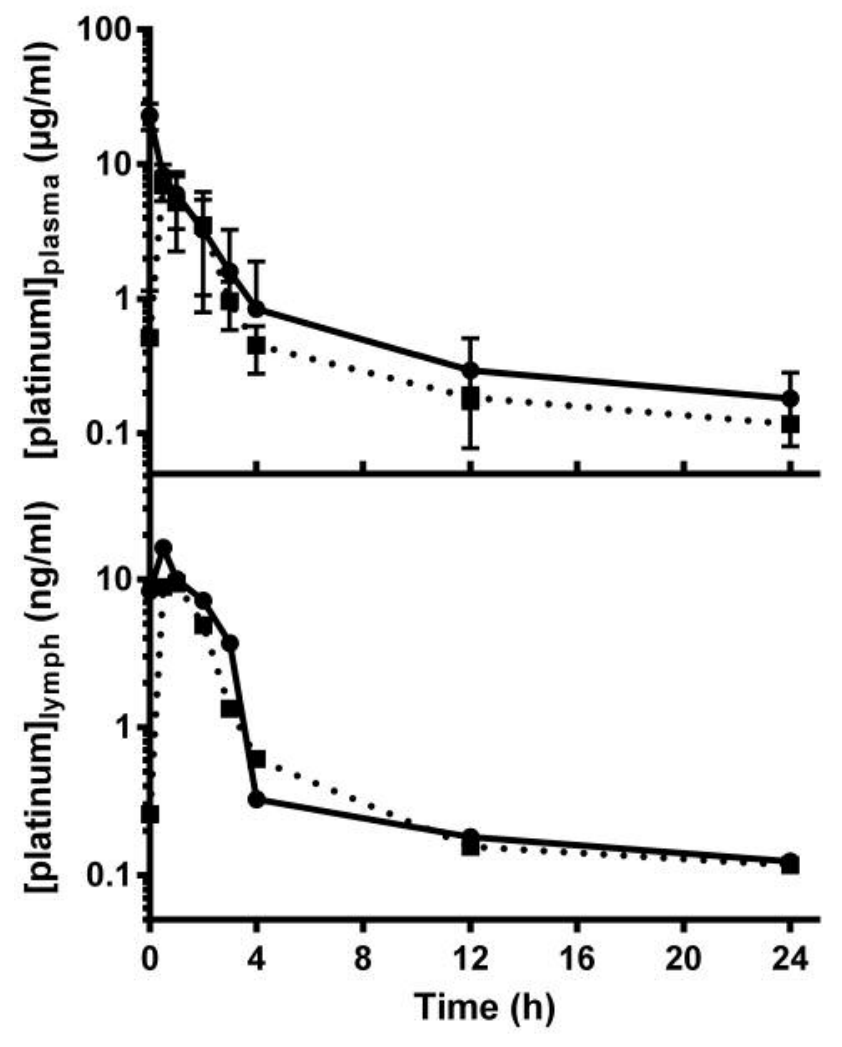

Figure 2. Time concentration curves of carboplatin $(14 \mathrm{mg} / \mathrm{kg})$ in plasma (top graph) and lymph (bottom graph) when delivered either i.v. (solid line) or s.c. (dotted line).

lymph to exposure in the plasma in the i.v. and s.c. groups was 0.787 and 1.96 , respectively. The $C_{\max }$ in lymph was comparable regardless of the route of delivery $(172 \pm 63 \mathrm{ng} / \mathrm{ml}$ following i.v. and $161 \pm 54 \mathrm{ng} / \mathrm{ml}$ when administered s.c.; $p=0.830$ ). Not surprisingly, plasma $\mathrm{C}_{\max }$ was significantly greater following i.v. delivery $(2,857 \pm 560 \mathrm{ng} / \mathrm{ml})$ than with s.c. delivery $(80.8 \pm 19.0 \mathrm{ng} / \mathrm{ml} ; p=0.0001$; Table I). The time to maximal concentration $\left(\mathrm{T}_{\max }\right)$ in plasma and lymph following s.c. delivery was quite similar $(3.0 \pm 1.2 \mathrm{~h}$ and $2.3 \pm 1.5 \mathrm{~h}$, respectively) while $\mathrm{T}_{\max }$ in lymph following i.v. delivery occurred at 30 minutes (Table I). Taken together, the data for i.v. and s.c. delivered docetaxel suggests that s.c. administration provides comparable, slightly higher lymphatic exposure with a lower plasma exposure based on $\mathrm{C}_{\max }$ and $\mathrm{AUC}_{0-24 \mathrm{~h}}$.

Plasma and lymph disposition of carboplatin following i.v. and s.c. administration at two dose levels. Following i.v. delivery of carboplatin at $14 \mathrm{mg} / \mathrm{kg}$, the $\mathrm{C}_{\max }$ in the plasma and lymph for total platinum was $23.0 \pm 5.1 \mu \mathrm{g} / \mathrm{ml}$ and $13.1 \pm 4.1 \mu \mathrm{g} / \mathrm{ml}$ (Figure 2, Table II). The $\mathrm{AUC}_{0-24 \mathrm{~h}}$ for plasma and lymph was $27.8 \pm 15.1 \mathrm{~h}^{*} \mu \mathrm{g} / \mathrm{ml}$ and $31.0 \pm 9.0 \mathrm{~h} * \mu \mathrm{g} / \mathrm{ml}$, respectively (Table

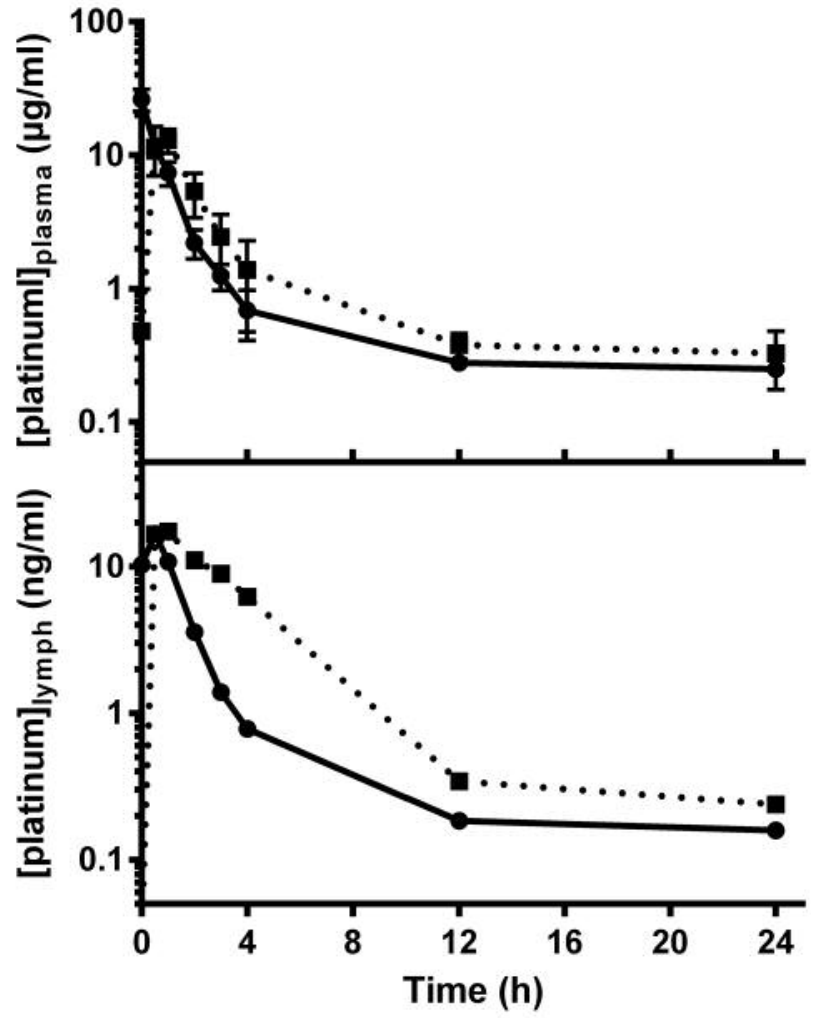

Figure 3. Time concentration curves of carboplatin $(28 \mathrm{mg} / \mathrm{kg})$ in plasma (top graph) and lymph (bottom graph) when delivered either i.v. (solid line) or s.c. (dotted line).

II). Thus, while the maximum concentration in lymph is lower following $i . v$. delivery, the total exposure over $24 \mathrm{~h}$ in lymph and plasma are comparable. When delivered s.c. at $14 \mathrm{mg} / \mathrm{kg}$, the carboplatin $\mathrm{C}_{\max }$ in the plasma and lymph was $7.22 \pm 1.9 \mu \mathrm{g} / \mathrm{ml}$ and $9.40 \pm 6.6 \mu \mathrm{g} / \mathrm{ml}$ (Table II). Twenty-four hour exposures in plasma and lymph following s.c. delivery were also comparable $\left(16.7 \pm 2.8 \mathrm{~h}^{*} \mu \mathrm{g} / \mathrm{ml}\right.$ and $22.8 \pm 2.7 \mathrm{~h} * \mu \mathrm{g} / \mathrm{ml}$, respectively) (Table II). Following s.c. administration of a $28 \mathrm{mg} / \mathrm{kg}$ carboplatin dose, there was a dose proportional increase in the plasma and lymph $\mathrm{C}_{\max }$ and $\mathrm{AUC}_{0-24 \mathrm{~h}}$ with values approximately twice those following the $14 \mathrm{mg} / \mathrm{kg}$ dose (Figure 3, Tables II and III). Similar to the $14 \mathrm{mg} / \mathrm{kg}$ s.c. dose, the lymph $\mathrm{C}_{\max }$ following $28 \mathrm{mg} / \mathrm{kg}$ s.c. was slightly higher than the plasma $\mathrm{C}_{\max }(17.3 \pm 1.6 \mu \mathrm{g} / \mathrm{ml}$ vs. $13.0 \pm 2.6 \mu \mathrm{g} / \mathrm{ml})$. Unexpectedly, a dose proportional increase in $\mathrm{C}_{\max }$ and $\mathrm{AUC}_{0-24 \mathrm{~h}}$ was not seen following the $28 \mathrm{mg} / \mathrm{kg}$ i.v. dose. However, the same trend in plasma versus lymph that was observed with the $14 \mathrm{mg} / \mathrm{kg}$ i.v. dose was seen in the $28 \mathrm{mg} / \mathrm{kg}$ i.v. dose with a higher plasma $\mathrm{C}_{\max }(26.2 \pm 4.9 \mu \mathrm{g} / \mathrm{ml}$ versus $16.7 \pm 3.0 \mu \mathrm{g} / \mathrm{ml}$ ) and comparable to 24-h exposure $\left(29.1 \pm 4.5 \mathrm{~h}^{*} \mu \mathrm{g} / \mathrm{ml}\right.$ in plasma versus $30.3 \pm 5.4 \mathrm{~h} * \mu \mathrm{g} / \mathrm{ml}$ in lymph) (Figure 3, Table III). By comparing the plasma 
Table II. Non-compartmental pharmacokinetics of carboplatin $(14 \mathrm{mg} / \mathrm{kg})$ in plasma and lymph when delivered either i.v. or s.c.

Carboplatin $14 \mathrm{mg} / \mathrm{kg}$

\begin{tabular}{|c|c|c|c|c|c|}
\hline \multirow[b]{2}{*}{ PK paramete } & & \multicolumn{2}{|c|}{ i.v. Admin } & \multicolumn{2}{|c|}{ s.c. Admin } \\
\hline & & $\begin{array}{c}\text { Plasma } \\
\text { ave (S.D.; n) }\end{array}$ & $\begin{array}{l}\text { Lymph } \\
\text { mean (SE) }\end{array}$ & $\begin{array}{c}\text { Plasma } \\
\text { ave (S.D.; n) }\end{array}$ & $\begin{array}{l}\text { Lymph } \\
\text { mean (SE) }\end{array}$ \\
\hline $\mathrm{C}_{\max }$ & $\mathrm{ng} / \mathrm{ml}$ & $22989(5099 ; 10)$ & $13102(4070)$ & $7218(1873 ; 6)$ & 9395 (657) \\
\hline $\mathrm{T}_{\max }$ & $\mathrm{h}$ & - & 0.5 & $0.9(0.6 ; 6)$ & 1 \\
\hline$\lambda_{\mathrm{z}}$ & $1 / \mathrm{h}$ & $0.057(0.024 ; 7)$ & 0.047 & $0.063(0.016 ; 6)$ & 0.078 \\
\hline $\mathrm{t}_{1 / 2}$ & $\mathrm{~h}$ & $14.1(5.6 ; 7)$ & 14.7 & $11.6(2.7 ; 6)$ & 8.9 \\
\hline $\mathrm{AUC}_{0-24 \mathrm{~h}}$ & $\mathrm{~h}^{*} \mathrm{ng} / \mathrm{ml}$ & $27798(15119 ; 7)$ & $30990(8960)$ & $16688(2763 ; 6)$ & $22783(2661)$ \\
\hline $\mathrm{AUC}_{0 \text {-inf }}$ & $\mathrm{h} * \mathrm{ng} / \mathrm{ml}$ & $30997(15517 ; 7)$ & 33619 & $18658(3084 ; 6)$ & 24287 \\
\hline $\mathrm{V}_{\mathrm{d}}$ & $1 / \mathrm{kg}$ & $11.7(7.0 ; 7)$ & & $7.61(1.80 ; 6)$ & \\
\hline $\mathrm{Cl}$ & $\mathrm{ml} / \mathrm{h} / \mathrm{kg}$ & $8.86(3.15 ; 7)$ & & $7.67(1.20 ; 6)$ & \\
\hline $\mathrm{F}$ & $\%$ & & & 60 & \\
\hline
\end{tabular}

Admin, administration; PK, pharmacokinetic; ave, average; S.D., standard deviation; SE, standard error; $\mathrm{C}_{\max }$, maximum plasma concentration observed; $\mathrm{T}_{\max }$, time of maximum plasma concentration observed; $\lambda_{\mathrm{z}}$, elimination rate constant; $\mathrm{AUC}_{0-24 \mathrm{~h}}$, area under the plasma concentration time curve from 0 to $24 \mathrm{~h} ; \mathrm{AUC}_{0 \text {-inf }}$, area under the plasma concentration time curve from $0 \mathrm{~h}$ to infinity; $\mathrm{V}_{\mathrm{d}}$, volume of distribution; $\mathrm{Cl}$, clearance; MRT, mean residence time; F, bioavailability.

Table III. Non-compartmental pharmacokinetics of carboplatin $(28 \mathrm{mg} / \mathrm{kg})$ in plasma and lymph when delivered either i.v. or s.c.

\begin{tabular}{|c|c|c|c|c|c|}
\hline \multicolumn{6}{|c|}{ Carboplatin $28 \mathrm{mg} / \mathrm{kg}$} \\
\hline \multirow[b]{2}{*}{ PK paramete } & & \multicolumn{2}{|c|}{ i.v. Admin } & \multicolumn{2}{|c|}{ s.c. Admin } \\
\hline & & $\begin{array}{c}\text { Plasma } \\
\text { ave (S.D.; n) }\end{array}$ & $\begin{array}{l}\text { Lymph } \\
\text { mean (SE) }\end{array}$ & $\begin{array}{c}\text { Plasma } \\
\text { ave (S.D.; n) }\end{array}$ & $\begin{array}{l}\text { Lymph } \\
\text { mean (SE) }\end{array}$ \\
\hline $\mathrm{C}_{\max }$ & $\mathrm{ng} / \mathrm{ml}$ & 26167 (4895; 4) & $16669(2945)$ & $13025(2563 ; 4)$ & $17325(1555)$ \\
\hline $\mathrm{T}_{\max }$ & $\mathrm{h}$ & - & 0.5 & $0.9(0.3 ; 4)$ & 1 \\
\hline$\lambda_{\mathrm{z}}$ & $1 / \mathrm{h}$ & $0.045(0.015 ; 3)$ & 0.074 & $0.063(0.029 ; 4)$ & 0.152 \\
\hline$t_{1 / 2}$ & $\mathrm{~h}$ & $11.5(4.9 ; 3)$ & 9.3 & $14.9(11.8 ; 4)$ & 4.6 \\
\hline $\mathrm{AUC}_{0-24 \mathrm{~h}}$ & $\mathrm{~h} * \mathrm{ng} / \mathrm{ml}$ & $29144(4480 ; 3)$ & 30255 (5379) & $36261(9844 ; 4)$ & $73950(29259)$ \\
\hline $\mathrm{AUC}_{0 \text {-inf }}$ & $\mathrm{h} * \mathrm{ng} / \mathrm{ml}$ & $34994(3692 ; 3)$ & 32380 & $43008(8399 ; 4)$ & 75521 \\
\hline $\mathrm{V}_{\mathrm{d}}$ & $1 / \mathrm{kg}$ & $19.5(7.6 ; 3)$ & & $18.7(16.7 ; 4)$ & \\
\hline $\mathrm{Cl}$ & $\mathrm{ml} / \mathrm{h} / \mathrm{kg}$ & $13.4(1.5 ; 3)$ & & $13.8(2.5 ; 4)$ & \\
\hline $\mathrm{F}$ & $\%$ & & & 124 & \\
\hline
\end{tabular}

Admin, administration; PK, pharmacokinetic; ave, average; S.D., standard deviation; SE, standard error; $\mathrm{C}_{\max }$, maximum plasma concentration observed; $\mathrm{T}_{\max }$, time of maximum plasma concentration observed; $\lambda_{\mathrm{z}}$, elimination rate constant; $\mathrm{AUC}_{0-24 \mathrm{~h}}$, area under the plasma concentration time curve from 0 to $24 \mathrm{~h} ; \mathrm{AUC}_{0 \text {-inf }}$, area under the plasma concentration time curve from $0 \mathrm{~h}$ to infinity; $\mathrm{V}_{\mathrm{d}}$, volume of distribution; $\mathrm{Cl}$, clearance; MRT, mean residence time; F, bioavailability.

carboplatin between the two administration routes, a significantly higher $\mathrm{C}_{\max }$ for both $14 \mathrm{mg} / \mathrm{kg}$ and $28 \mathrm{mg} / \mathrm{kg}$ doses $(p<0.0001$ and $p=0.003$, respectively) was found, but the difference was insignificant in $\mathrm{AUC}_{0-24 \mathrm{~h}}$ ( $p=0.105$ and $p=0.297$ ) (Tables II and III). Taken together, these data suggest that the maximum lymph concentration and the $24 \mathrm{~h}$ lymph exposure are comparable with either $i . v$. or s.c. administration and there is no apparent accumulation of carboplatin in lymph. While it might appear that there is substantial accumulation in lymph following s.c. delivery of the $28 \mathrm{mg} / \mathrm{kg}$ dose $\left(\mathrm{AUC}_{0-24}\right.$ of $74.0 \pm 29.3 \mathrm{~h} * \mu \mathrm{g} / \mathrm{ml} v s$. $36.3 \pm 9.8 \mathrm{~h} * \mu \mathrm{g} / \mathrm{ml}$ in plasma) it is important to note the substantial degree of variability in the lymph data that was due to a single rat with a high concentration measured at a late 
time point. Additionally, this large apparent increase in exposure was not seen following the $14 \mathrm{mg} / \mathrm{kg}$ s.c. dose, which also suggests that the $\mathrm{AUC}_{0-24 \mathrm{~h}}$ data in the $28 \mathrm{mg} / \mathrm{kg}$ s.c. group should be interpreted with caution. Plasma exposures over $24 \mathrm{~h}$ are comparable between administration routes but, not surprisingly, maximum plasma concentrations are higher following i.v. delivery.

\section{Discussion}

Non-traditional s.c. delivery of docetaxel achieves intended lymphatic accumulation greater than that of traditional i.v. delivery; yet there was no apparent lymphatic accumulation with s.c. delivery of carboplatin in this rodent model. The different pharmacokinetic patterns between these two drugs may be explained by their differing physiochemical properties. Lymph is a lipophilic-rich fluid; docetaxel is lipophilic and carboplatin has partial hydrophilicity. The finding of lymphatic accumulation with s.c. delivery of docetaxel has a possible implication for dosing strategies of at least docetaxel antineoplastics for susceptible cancers that metastasize predominantly via lymphatic pathways. Additionally, while the area under the time concentration curve in plasma with either i.v. or s.c. dosing of carboplatin $(28 \mathrm{mg} / \mathrm{kg})$ and docetaxel were similar, the maximum plasma concentration measured was less with s.c. dosing for both chemotherapeutics. This may also have possible application for cancer patients susceptible to toxicity resulting from peak maximum hemovascular chemotherapy concentrations that may be lessened via s.c. delivery while maintaining comparable overall plasma drug exposures.

Use of locally delivered chemotherapy has been explored extensively for dogs with naturally occurring canine tumors $(2,3,6,23-25)$. Wound implantation of cisplatinimpregnated open-cell polylactic acid (OPLA-Pt) was shown to be tolerated and effective against metastasis and local recurrence in dogs receiving limb-sparing surgery $(2,6,23$ 25). Following wound implantation of either 82 or $54 \mathrm{mg} / \mathrm{m}^{2}$ OPLA-Pt, the combined mean area under the curve for total serum platinum concentration was almost 30 times greater than that after a single $i . v$. infusion of $70 \mathrm{mg} / \mathrm{m}^{2}$ of cisplatin (23); in another study dogs receiving single s.c. cisplatin injections of $70 \mathrm{mg} / \mathrm{m}^{2}$ had detectable serum platinum concentrations all through the 21 days measured (26). Simcock et al. reported a median survival time of 365 days in 17 client-owned dogs having curative-intent surgical treatment for naturally occurring primary bone tumors and which received only a single adjuvant slow s.c. infusion of $300 \mathrm{mg} / \mathrm{m}^{2}$ carboplatin over a 3 to 7 day delivery period (3). This is comparable to historical median survival times of 1014 months following four $300 \mathrm{mg} / \mathrm{m}^{2}$ i.v. adjuvant carboplatin doses delivered every three weeks (3) and demonstrates a poorly understood benefit of non-traditional extravascular carboplatin delivery resulting in comparable tumor control at doses less than traditionally given. Extravascular delivered carboplatin experiences lymphatic uptake, which may explain, in part, the observed therapeutic advantage. Advancing the concept of locally delivered chemotherapeutics, several studies have also demonstrated lymphatic targeting of formulations of locally delivered chemotherapeutics (27-37). Effectiveness of lymphatic penetration of these various formulations had been inferred from indirect lymphatic sampling methods to estimate the amount of product penetrating the lymphatics via lymph node tissue sampling, but have not been measured in lymph fluid prior to this study $(8,21,38)$. Definitive lymph fluid sampling to assess lymphatic pharmacokinetics of locally delivered drug has occurred very rarely to date $(10,14,39)$.

It is unknown what injection site reaction might result from slow sustained s.c. delivery of some chemotherapeutics. Carboplatin has been described as a possible irritant if extravasation following bolus i.v. delivery in people. Effects of extravasated docetaxel are less defined with case reports describing irritant events as vesicant-type reactions (40). Future studies are planned assessing the long-term toxicities associated with s.c. delivery of docetaxel in this model.

This model is unique for several reasons: (i) Techniques employed in this study permitted direct lymph sampling in awake and freely mobile animals, which may potentially be more representative of actual lymph circulatory patterns, as opposed to studies requiring sustained general anesthesia of the patient for lymph sampling or studies sampling lymph node tissue without lymph fluid for drug measurements. (ii) This model permits free unrestricted movement of the animal that also increases lymph pharmacokinetic accuracy compared to studies strictly impeding animal movement. Lymph circulation moves as the function of both the intrinsic and extrinsic lymphatic pumps. The extrinsic lymphatic pump is partially dependent upon contraction of surrounding skeletal muscle, movement of body systems, including peristaltic bowel, lung insufflation and pulsation of adjacent arteries. (iii) All animals had the same surgical catheterizations performed on each creating uniformity of the investigative insult though increasing the technical challenge in performing these studies (14).

A challenge of this study is that thoracic duct catheterizations are not always successful, as has been reported this procedure is successful $80 \%$ of the time that echoes this group's experience (41). Another challenge of this model is the finite amount of time possible for serial lymph and blood collection prior to lymph catheter clotting and iatrogenic lifethreatening hypoalbuminemia and anemia without active replacement measures. Future studies are planned to utilize sequential lymph and blood sampling at different time points in a larger population of cannulated rats. Additional work is also needed to correlate lymphatic and hemovascular 
pharmacokinetics with pharmacodynamics in tumor-bearing animal models to better understand the impact of prolonged drug exposure from greater AUCs versus the impact of greater $\mathrm{C}_{\text {max }}$ for optimal antineoplastic effect.

In conclusion, this study demonstrates that non-traditional s.c. delivery of docetaxel achieves enhanced lymphatic accumulation greater than that of traditional i.v. delivery and that paired serial blood and lymph collection is achievable in a rodent model.

\section{Acknowledgements}

This work was supported by ACS IRG \#57-001-53 from the American Cancer Society and in part by the Flint Animal Cancer Center and the University of Colorado Cancer Center Shared Resource Support Grant (P30CA046934).

The manuscript does not contain clinical studies or patient data.

\section{References}

1 Ehrhart N, Dernell WS, Ehrhart EJ, Hutchison JM, Douple EB, Brekke JH, Straw RC and Withrow SJ: Effects of a controlledrelease cisplatin delivery system used after resection of mammary carcinoma in mice. Am J Vet Res 60(11): 1347-1351, 1999.

2 Withrow SJ, Liptak JM, Straw RC, Dernell WS, Jameson VJ, Powers BE, Johnson JL, Brekke JH and Douple EB: Biodegradable cisplatin polymer in limb-sparing surgery for canine osteosarcoma. Ann Surg Oncol 11(7): 705-713, 2004.

3 Simcock JO, Withers SS, Prpich CY, Kuntz CA and Rutland BE: Evaluation of a single subcutaneous infusion of carboplatin as adjuvant chemotherapy for dogs with osteosarcoma: 17 cases (2006-2010). J Am Vet Med Assoc 241(5): 608-614, 2012.

4 Emerich DF, Snodgrass P, Lafreniere D, Dean RL, Salzberg H, Marsh J, Perdomo B, Arastu M, Winn SR and Bartus RT: Sustained release chemotherapeutic microspheres provide superior efficacy over systemic therapy and local bolus infusions. Pharm Res 19(7): 1052-1060, 2002.

5 Theon AP, Wilson WD, Magdesian KG, Pusterla N, Snyder JR and Galuppo LD: Long-term outcome associated with intratumoral chemotherapy with cisplatin for cutaneous tumors in equidae: 573 cases (1995-2004). J Am Vet Med Assoc 230(10): 1506-1513, 2007.

6 Withrow S, Straw R, Brekke J, Powers B, Cooper M, Ogilvie G, Lafferty M, Jameson V, Douple E, Johnson J and Dernell W: Slow release adjuvant cisplatin for treatment of metastatic canine osteosarcoma. Eur J Exp Musculoskel Res 4: 105-110, 1995.

7 The microcirculation and lymphatic system: capillary fluid exchange, interstitial fluid, and lymph flow. In: Guyton and Hall Textbook of Medical Physiology (Hall JE ed.). Philadelphia: Saunders Elsevier, 2011.

8 Kim C-K, Lee M-K, Han J-H and Lee B-J: Pharmacokinetics and tissue distribution of methotrexate after intravenous injection of differently charged liposome-entrapped methotrexate to rats. International Journal of Pharmaceutics 108(1): 21-29, 1994.

9 Tokunaga Y, Iwasa T, Fujisaki J, Sawai S and Kagayama A: Liposomal sustained-release delivery systems for intravenous injection. Ii. Design of liposome carriers and blood disposition of lipophilic mitomycin c prodrug-bearing liposomes. Chem Pharm Bull (Tokyo) 36(9): 3557-3564, 1988.

10 Parker RJ, Hartman KD and Sieber SM: Lymphatic absorption and tissue disposition of liposome-entrapped (14c)adriamycin following intraperitoneal administration to rats. Cancer Res 41(4): 1311-1317, 1981.

11 Zawieja D: Lymphatic biology and the microcirculation: Past, present and future. Microcirculation 12(1): 141-150, 2005.

12 Ran S, Volk L, Hall K and Flister MJ: Lymphangiogenesis and lymphatic metastasis in breast cancer. Pathophysiology 17(4): 229-251, 2010.

13 Kinnunen HM and Mrsny RJ: Improving the outcomes of biopharmaceutical delivery via the subcutaneous route by understanding the chemical, physical and physiological properties of the subcutaneous injection site. J Control Release 182: 22-32, 2014.

14 Dahlberg AM, Kaminskas LM, Smith A, Nicolazzo JA, Porter CJ, Bulitta JB and McIntosh MP: The lymphatic system plays a major role in the intravenous and subcutaneous pharmacokinetics of trastuzumab in rats. Mol Pharm 11(2): 496-504, 2014.

15 Caliph SM, Cao E, Bulitta JB, Hu L, Han S, Porter CJ and Trevaskis NL: The impact of lymphatic transport on the systemic disposition of lipophilic drugs. J Pharm Sci 102(7): 2395-2408, 2013.

16 Kaminskas LM and Porter CJ: Targeting the lymphatics using dendritic polymers (dendrimers). Adv Drug Deliv Rev 63(1011): 890-900, 2011.

17 Oussoren C and Storm G: Liposomes to target the lymphatics by subcutaneous administration. Adv Drug Deliv Rev 50(1-2): 143$156,2001$.

18 Gavini E, Manunta L, Giua S, Achenza G and Giunchedi P: Spray-dried poly(d,l-lactide) microspheres containing carboplatin for veterinary use: In vitro and in vivo studies. AAPS PharmSciTech 6(1): E108-114, 2005.

19 Kim JK, Won YW, Lim KS and Kim YH: Low-molecular-weight methylcellulose-based thermo-reversible gel/pluronic micelle combination system for local and sustained docetaxel delivery. Pharm Res 29(2): 525-534, 2012.

20 Yang Y, Wang J, Zhang X, Lu W and Zhang Q: A novel mixed micelle gel with thermo-sensitive property for the local delivery of docetaxel. J Control Release 135(2): 175-182, 2009.

21 Tiantian Y, Wenji Z, Mingshuang S, Rui Y, Shuangshuang S, Yuling M, Jianhua Y, Xinggang Y, Shujun W and Weisan P: Study on intralymphatic-targeted hyaluronic acid-modified nanoliposome: Influence of formulation factors on the lymphatic targeting. Int J Pharm 471(1-2): 245-257, 2014.

22 Gustafson DL, Long ME, Zirrolli JA, Duncan MW, Holden SN, Pierson AS and Eckhardt SG: Analysis of docetaxel pharmacokinetics in humans with the inclusion of later sampling time-points afforded by the use of a sensitive tandem lcms assay. Cancer Chemother Pharmacol 52(2): 159-166, 2003.

23 Straw RC, Withrow SJ, Douple EB, Brekke JH, Cooper MF, Schwarz PD, Greco DS and Powers BE: Effects of cisdiamminedichloroplatinum ii released from d,l-polylactic acid implanted adjacent to cortical allografts in dogs. J Orthop Res 12(6): 871-877, 1994.

24 Mehl ML, Seguin B, Dernell WS, Lafferty M, Kass PH and Withrow SJ: Survival analysis of one versus two treatments of local delivery cisplatin in a biodegradable polymer for canine osteosarcoma. Vet Comp Oncol 3(2): 81-86, 2005. 
25 Liptak JM, Dernell WS, Ehrhart N, Lafferty MH, Monteith GJ and Withrow SJ: Cortical allograft and endoprosthesis for limbsparing surgery in dogs with distal radial osteosarcoma: A prospective clinical comparison of two different limb-sparing techniques. Vet Surg 35(6): 518-533, 2006.

26 Dernell WS, Withrow SJ, Straw RC and Lafferty MH: Adjuvant chemotherapy using cisplatin by subcutaneous administration. In Vivo 11(4): 345-350, 1997.

27 Shin SB, Cho HY, Kim DD, Choi HG and Lee YB: Preparation and evaluation of tacrolimus-loaded nanoparticles for lymphatic delivery. Eur J Pharm Biopharm 74(2): 164-171, 2010.

28 Ling R, Yu L, Yao Q, Chen T, Zhu DS, Jun Y and Chen JH: Lymphatic chemotherapy induces apoptosis in lymph node metastases in a rabbit breast carcinoma model. J Drug Targeting 13(2): 137-142, 2005.

29 Lu H, Li B, Kang Y, Jiang W, Huang Q, Chen Q, Li L and Xu $\mathrm{C}$ : Paclitaxel nanoparticle inhibits growth of ovarian cancer xenografts and enhances lymphatic targeting. Cancer Chemother Pharmacol 59(2): 175-181, 2007.

30 Cohen MS, Cai S, Xie Y and Forrest ML: A novel intralymphatic nanocarrier delivery system for cisplatin therapy in breast cancer with improved tumor efficacy and lower systemic toxicity in vivo. Am J Surg 198(6): 781-786, 2009.

31 Cai S, Xie Y, Davies NM, Cohen MS and Forrest ML: Pharmacokinetics and disposition of a localized lymphatic polymeric hyaluronan conjugate of cisplatin in rodents. J Pharm Sci 99(6): 2664-2671, 2009.

32 Cai S, Xie Y, Bagby TR, Cohen MS and Forrest ML: Intralymphatic chemotherapy using a hyaluronan-cisplatin conjugate. J Surg Res 147(2): 247-252, 2008

33 Chen J, Yao Q, Li D, Zhang B, Li L and Wang L: Chemotherapy targeting regional lymphatic tissues to treat rabbits bearing vx2 tumor in the mammary glands. Cancer Biol Ther 7(5): 721-725, 2008 .

34 Luo G, Yu X, Jin C, Yang F, Fu D, Long J, Xu J, Zhan C and Lu W: Lyp-1-conjugated nanoparticles for targeting drug delivery to lymphatic metastatic tumors. Int J Pharm 385(1-2): 150-156, 2010.
35 Akamo Y, Mizuno I, Yotsuyanagi T, Ichino T, Tanimoto N, Yamamoto T, Nagata M, Takeyama H, Shinagawa N, Yura J and Manabe T: Chemotherapy targeting regional lymph nodes by gastric submucosal injection of liposomal adriamycin in patients with gastric carcinoma. Jpn J Cancer Res 85(6): 652-658, 1994.

36 Chen J, Wang L, Yao Q, Ling R, Li K and Wang H: Drug concentrations in axillary lymph nodes after lymphatic chemotherapy on patients with breast cancer. Breast Cancer Res 6(4): R474-477, 2004.

37 Venable RO, Worley DR, Gustafson DL, Hansen RJ, Ehrhart EJ, 3rd, Cai S, Cohen MS and Forrest ML: Effects of intratumoral administration of a hyaluronan-cisplatin nanoconjugate to five dogs with soft tissue sarcomas. Am J Vet Res 73(12): 19691976, 2012.

38 Zor M, Yildirim I, Basal S, Yaman H, Ozturk M, Irkilata CH, Goktas S and Dayanc M: Intralymphatic delivery of platinumbased chemotherapeutics is possible: An experimental study. J Cancer Res Clin Oncol 138(10): 1679-1682, 2012.

39 Lindner P, Heath DD, Shalinsky DR, Howell SB, Naredi P and Hafstrom L: Regional lymphatic drug exposure following intraperitoneal administration of 5-fluorouracil, carboplatin, and etoposide. Surg Oncol 2(2): 105-112, 1993.

40 Barbee MS, Owonikoko TK and Harvey RD: Taxanes: Vesicants, irritants, or just irritating? Ther Adv Med Oncol 6(1): 16-20, 2014.

41 Boyd M, Risovic V, Jull P, Choo E and Wasan KM: A stepwise surgical procedure to investigate the lymphatic transport of lipidbased oral drug formulations: Cannulation of the mesenteric and thoracic lymph ducts within the rat. J Pharmacol Toxicol Methods 49(2): 115-120, 2004
Received August 5, 2016

Revised August 23, 2016

Accepted August 25, 2016 